\title{
The unmet needs of depressed adolescent patients: how race, gender, and age relate to evidence-based depression care in rural areas
}

\author{
Lisa M. Hooper \\ Department of Educational Studies in Psychology, Research Methodology, and Counseling, \\ The University of Alabama, Graves Hall, Tuscaloosa, AL, USA
}

\begin{abstract}
Background: Studies have established that many depressed adolescent patients do not receive optimal mental health care. Specifically, depression in primary-care settings is underrecognized, undertreated, and stigmatized. Although the seriousness and prevalence of adolescent depression is well known to primary-care physicians, its assessment, diagnosis, and treatment remains a significant problem in general and in rural communities in particular. Aims and discussion: In this article, the author accomplishes three aims: (1) summarizes the most current evidence-based guidelines for depression care for adolescents in primary-care settings, (2) reviews the empirical literature on how key patient demographic variables (race, gender, and age) may be correlated with and predictive of variations in evidence-based depression care (assessment, diagnosis, and treatment) for adolescent patients, particularly in rural areas, and (3) provides implications for translating empirical research findings to evidence-based depression care in rural primary-care settings.
\end{abstract}

Key words: adolescents; depression treatment; diagnosis; gender; race; rural mental health care

Received 19 May 2009; accepted 13 June 2010; first published online 12 August 2010

\section{Introduction}

For adolescents (ages 12-18), depression is one of the most common clinical disorders. Prevalence rates of depression in adolescents have been estimated at 3-5\% (American Academy of Child and Adolescent Psychiatry, 1998; U.S. Department of Health and Human Services, 2001; Harrington, 2002; Kessler et al., 2003), and lifetime prevalence of major depressive disorder among adolescents may be as high as $20 \%$ (Williams et al., 2009). Furthermore, depression in adolescence leads to significant disability, morbidity, and mortality (U.S. Department of Health and Human Services, 2001;

\footnotetext{
Correspondence to: Lisa M. Hooper, Associate Professor, Department of Educational Studies in Psychology, Research Methodology, and Counseling, The University of Alabama, Box 870231, 315 B Graves Hall, Tuscaloosa, AL 35487-0231, USA. Email: lhooper@bamaed.ua.edu
}

C) Cambridge University Press 2010
Harrington, 2002; Kessler et al., 2003). Despite these poor long-term outcomes, depression in adolescents continues to be underrecognized, undertreated, and stigmatized (Cheng et al., 1993; Walker et al., 2002; Stein et al., 2006; Zuckerbrot et al., 2007a; 2007b). According to the National Survey on Drug Use and Health, $60 \%$ of adolescents who reported having at least one depressive episode in the previous year failed to receive adequate treatment for their depression (Substance Abuse and Mental Health Services Administration, 2004).

The lack of mental health services in rural communities is particularly severe (Martin and Leslie, 2003). Thus, the need for quality adolescent mental health services, including evidence-based depression care, particularly in rural communities, is urgent and significant (Greenberg et al., 2006). Moreover, disentangling the factors that may relate to or impinge upon evidence-based care is an important area of study. 
Primary-care physicians are often the first point of contact for adolescents suffering from mental health symptoms and disorders, including depression (Neighbors et al., 2007). Unfortunately, most depressed patients seen in primary-care settings receive less than optimal care (Kessler et al., 2003). Although there are established evidence-based guidelines for depression care (operationalized as assessment, diagnosis, and treatment) for adolescent patients, not all primary-care physicians follow - or are even aware of - these guidelines. Primarycare physicians treating depression in rural settings have even greater challenges and fewer treatment options than do counterparts in urban settings (President's New Freedom Commission on Mental Health, n.d.). Specifically, physicians who work in rural communities face unique and overwhelming challenges in providing quality care (Cuffe et al., 1995; Stein et al., 2006). For example, a study of physicians working in rural counties in the United States reported that $55 \%$ of the communities had no psychiatrists, psychologists, or social workers (Pion et al., 1997). Consequently, primary-care physicians working in rural settings may lack a mental health specialist with whom to consult or to whom to refer (Shirley, 1995; Pion et al., 1997; Satcher, 1999; Merwin et al., 2003). Thus, primarycare physicians in rural settings often serve as sole providers of adolescent mental health care.

Given that many rural primary-care physicians often fail to recognize and optimally treat depression (Cheng et al., 1993; Walker et al., 2002; Stein et al., 2006; Zuckerbrot et al., 2007a), uncovering the factors that may influence depression recognition and optimal depression care is an important area of consideration and review. The literature suggests that patient factors such as race, gender, and age may help explain variation in the recognition and optimal treatment of adolescent mental health symptoms, including depression (American Psychiatric Association, 1994; Roberts et al., 1997; Centers for Disease Control and Prevention, 2000; Nguyen et al., 2007; Agency for Healthcare Research and Quality, 2009).

\section{The current review}

The purpose of this article is threefold: (1) to review the most up-to-date guidelines on evidence-based depression care for adolescent patients; (2) to review demographic factors (race, gender, and age) that may be correlated with or predictive of rural primary-care physicians' assessment, diagnostic, and treatment decisions for depression in adolescent patients; and (3) to discuss implications for practice. The three major sections of this article attend to these three topics.

This review is directed toward practitioners and researchers interested in the most current evidence-based guidelines for depression. It is relevant to a range of rural communities, providers, and researchers who work with adolescent patients and make decisions - at the bedside or more broadly (ie, inform policy decisions) related to evidence-based treatment.

\section{Location of studies}

To inform this review - and thus the location of studies - that have reported on evidence-based detection, assessment, and treatments for depression in adolescents seen in primary-care settings, the following databases were searched: PubMed, PsychInfo, Social Service Abstracts, National Institutes of Health Public Access, and Agency for Healthcare Research and Quality. The search procedure identified published articles whose titles or abstracts include terms related to evidence-based depression care for adolescents separately and paired with demographic terms (age, race, and gender). Specific databases were used (PubMed, the National Institute of Mental Health Public Access, American Academy of Child and Adolescent Psychiatry, and the American Psychiatric Association) to search for reviews related to evidence-based guidelines for depression care and for all articles related to guidelines for the management of adolescent depression in primary care (GLAD-PC), and the treatment for adolescents with depression study (TADS) studies. These procedures identified 40 articles.

\section{Evidence-based depression care}

Although the seriousness and prevalence of adolescent depression is well known to primary-care physicians, its detection (ie, assessment), diagnosis, and treatment remains a significant problem (Ryan, 2005; Stein et al., 2006). For the primary-care provider who is treating a depressed adolescent patient, there are multiple possible 
decision outcomes (ie, treatment decisions) relative to the published depression care guidelines, such as assessment, diagnosis, education, and the recommendation of appropriate evidence-based treatments. This section discusses these potential evidence-based depression care decision outcomes for adolescent patients.

\section{Assessment}

Because of the limited time available in primarycare settings and the potential benefits of screening for depression in adolescent patients, guidelines, and recommendations (Cheung et al., 2005; Zuckerbrot and Jensen, 2006) have been established. Evidence-based guidelines recommend that primary-care physicians screen for depression among adolescent patients (age 12-18 years) (Elster and Kuznets, 1994; Olson et al., 2001; Gadomski et al., 2003; Cheung et al., 2005; Richardson and Katzenellenbogen, 2005; Cheung et al., 2007; 2008; Zuckerbrot et al., 2007b; AHRQ, 2009). Specifically, the recently published guidelines by the U.S. Preventive Services Task Force (2009) noted the criticality of assessing all adolescent patients for depression. For example, specific primary-care guidelines advocate a systematic protocol (eg, Beck Depression Inventory, Patient Health Questionnaire-Adolescents, and Center for Epidemiological Study Depression Scale) to identify adolescents with risk factors (eg, suicidal ideation) for depression (American Academy of Child and Adolescent Psychiatry, 1998; Gadomski et al., 2003; Cheung et al., 2007; Cheung et al., 2008). Assessing depression can be difficult in general, particularly in conjunction with a medical illness. Since adolescent patients who present to the physician's office are likely to have a medical illness as well, case complexity may influence assessment and detection. Thus, physicians are sometimes faced with multiple conditions presented by the patient, including physical and psychological conditions. In addition to screening for depression, assessment and medical evaluation may include lab tests or imaging studies to evaluate whether there are medical causes of depression symptoms (eg, hypothyroidism). Other assessments may include questions about family history of depression, prior treatment for mental disorders (eg, bipolar disorder), or current, or previous suicidal ideation (Cheung et al., 2008).

\section{Diagnosis}

Following assessment, the first step in accurately and optimally treating depression is making the correct diagnosis. According to Frank et al. (2003), physicians fail to detect depression in approximately one-third to one-half of patients who meet the criteria for depression. The diagnosis of depression in adolescent patients may be complicated because the presentation and symptomatology in adolescents differ from those in adults. For example, unlike depression in adults, depression in adolescents may present with symptoms related to irritability, failure to make expected weight gains, decline in academic functioning, and acting out (Richardson and Katzenellenbogen, 2005; Zuckerbrot et al., 2007b; Cheung et al., 2008). This difference in presentation may obscure primary-care physicians' ability to accurately and efficiently diagnose depression in adolescents if physicians are looking for adult-like symptomatology.

Racial and cultural factors may also impinge upon a physician's ability to establish an accurate diagnosis. For example, there may be variations in the presentation of symptomatology among cultures, with somatic symptoms being reported rather than emotional symptoms (Richardson and Katzenellenbogen, 2005). Some cultures stigmatize discussing and experiencing a mental health disorder; as a result, many adolescents and their parents may be reluctant to report their symptoms. Thus, accurately diagnosing depression can be time consuming and challenging.

Insufficient training and experience may also impede accurately diagnosing depression. In a recent national survey, $46 \%$ of primary-care physicians indicated that they lacked the necessary knowledge, training, and confidence in their ability to recognize depression among adolescents (Olson et al., 2001). Other (ie, non-primary-care) physicians have reported lacking adequate time to conduct a comprehensive psychiatric history. In addition, primary-care physicians may struggle to determine whether particular symptoms are due to medical illnesses, medications, or depression. Medications for medical conditions may also be associated with mood changes, but it is often difficult to disentangle whether a specific drug is contributing to depression.

\section{Treatment}

In the National Survey on Drug Use and Health, of the adolescents who reported a history 
of a depressive episode in the past year, $60 \%$ failed to receive adequate evidence-based treatment for their depression (Substance Abuse and Mental Health Services Administration, 2004). Owing to the limited time in primary-care settings, some physicians may delimit their treatment of depression to assessment and referral, although in the context of rural settings a referral to a specialty mental healthcare provider may be unusually complicated and challenging because of limited availability. In addition, while some disagreement still exists regarding the optimal treatment approach for depression in children and adolescents - particularly the use of medications - evidence-based guidelines for the treatment of depression in primary-care settings have been created and put forward (American Academy of Child and Adolescent Psychiatry, 1998; Gadomski et al., 2003; Cheung et al., 2007; Zuckerbrot et al., 2007a).

GLAD-PC help primary-care physicians determine optimal treatment of depression in adolescents (Cheung et al., 2007; Zuckerbrot et al., 2007b). According to GLAD-PC, optimal treatment of depression in adolescents would include 'scientifically tested and proven treatments.' Thus, primarycare physicians' treatment of adolescents might include evidence-based pharmacotherapy, educational counseling, or evidence-based psychotherapy (cognitive behavioral therapy (CBT; Brent et al., 1997) or interpersonal psychotherapy (IPT; Mufson et al., 1999)) - or some combination of the three (Zuckerbrot and Jensen, 2006). However, all of these evidence-based treatment strategies must include patient education (Naqvi, 2004; Richardson and Katzenellenbogen, 2005; Zuckerbrot et al., 2007a). For example, pharmacotherapy without educating the patient on how to take the medication and the possible side effects is incomplete and considered less than quality or optimal depression care. Education about depression (eg, signs and symptomatology) is also an essential component of optimal evidence-based depression care (Elster and Kuznets, 1994).

With regard to the continued debate related to medication treatment (see U.S. Preventive Services Task Force, 2009) and the efficacy of other treatments for adolescent depression, several reviews, and studies sponsored by the National Institute of Mental Health have concluded that psychotherapy, medication, and combination treatments are appropriate and efficacious for depression in adolescents (Cheung et al., 2008). In addition, reviews conducted by the American Academy of Child and Adolescent Psychiatry and the American Psychiatric Association contend that the benefits of antidepressants outweigh the risks for the treatment of depression in adolescents. However, concurrent with the benefits of treating adolescent patients with antidepressants is the risk of increased suicidality (Williams et al., 2009).

A recent meta-analysis investigated the risk-tobenefit ratio for the use of antidepressant medication with adolescents (Bridge et al., 2005). The study authors concluded that six times more adolescents would benefit from medication than would be harmed. Although the evidence is still building, findings from the TADS indicate that combination therapy (CBT and medication (specifically, fluoxetine)) were superior to CBT or medication alone Cheung et al. (2008). Findings from this study also established that monotherapy medication (fluoxetine) was more effective than monotherapy CBT, and monotherapy CBT was more effective than a placebo. Other studies have established preliminarily that both IPT and CBT are effective (Cheung et al., 2007). Moreover, a few studies have found preliminarily that using CBT in primary-care settings has produced positive outcomes in reducing depression symptoms (Asarnow et al., 2005; Clarke et al., 2005). Surprisingly, Himelhoch and Ehrenreich (2007) reported that primary-care physicians are more likely than psychiatrists to provide psychotherapy to some of their patients.

Although primary-care physicians prescribe a range of antidepressants, fluoxetine is considered the first-line medication treatment for adolescents (Cheung et al., 2007; Zuckerbrot et al., 2007a; Cheung et al., 2008). Of significance, prescribing a medication as part of treatment requires appropriate monitoring of suicidality and potential adverse side effects. Recent evidence suggests that some primary-care physicians are reluctant to prescribe medication as their initial treatment for adolescent depression (Probst et al., 2004; Bridge et al., 2005; Cheung et al., 2008). At the same time, many physicians working in rural primary-care settings report a lack of referral availability (Rushton et al., 2000). GLAD-PC has particular relevance for rural primary-care physicians, who 
often have nowhere or no one to whom they can refer depressed adolescent patients.

\section{Effects of demographic factors on adolescent depression care}

\section{Race}

Given that by the year $2025,48 \%$ of all the US youth and adolescent population will consist of racial minorities, disentangling the influence of race on depression care is an important task that needs to be pursued with rigorous longitudinal and experimental research designs. The influence of the patient's race on the physician's treatment decision for adult populations has already been established. In the seminal study conducted by Schulman and colleagues (Schulman et al., 1999), black patients were less likely to receive a recommendation for cardiac catherization than white patients.

The influence of race on physicians' treatment decisions for adolescent patients also appears to be clear. Several studies on race and differences in the treatment of psychiatric disorders among adolescents demonstrate a clear trend toward the undertreatment of African Americans, possibly as a result of referral bias or lack of physician cultural competence (Cuffe et al., 1995). In one study on variation in care (Zuckerbrot et al., 2007a), researchers found that depression care for adolescents differed depending on race: black adolescents in the study were less likely to receive depression care than their white counterparts (30\% versus $45 \%$, respectively, received care). Other research shows that race may influence the amount of time physicians spend with patients presenting for depression care. In one recent study (Olfson et al., 2009), physicians spent more time with depressed white patients than with depressed non-Hispanic black patients.

The combination of poverty and racial minority status may also serve as a barrier to depression care. Many rural communities such as the southern region contain some of the poorest black children and families in the United States (Davis, 2000). These communities - consisting of a disproportionate number of poor black families - lack the resources and services to support adequate mental and medical care, including education, transportation, and recreation. Black
Americans are 'overrepresented in high-need populations, have reduced access to mental health services, and often receive poorer quality care than whites' (Williams et al., 2007: 305). Therefore, the relation between race and receiving optimal depression care may be a function of barriers to care rather than primary-care physician behavior.

The cultural bias of the physician is another major contributor to health disparities (Ryan, 2005). Some providers may be more sensitive to certain patient factors than others. For example, black providers might be less likely than white providers to have negative stereotypes regarding black patients with depression. As a result, they might be more likely to recommend evidencebased counseling for their black patients.

Similarly, the provider's cultural frame of reference may influence how the physician interprets presenting signs and symptomatology regardless of the patient's race (Nguyen et al., 2007). For example, in a recent study examining physicians' decisions for depression care (Epstein et al., 2008), the physician's race was significantly associated with the decision to prescribe an antidepressant: white American physicians were more likely to prescribe a selective serotonin reuptake inhibitor than black American physicians (odds ratio $=4.21$ versus 3.89, respectively). In this study, white American physicians were also more likely to ask adult depressed patients about suicidality than black American physicians (odds ratio $=2.37$ versus 1.87 , respectively). Finally, in this study, the physician's race was also significantly related to referral behavior: white American physicians were more likely than black American physicians to refer depressed patients. Thus, not only can patient race influence depression care, but also physician race can influence depression care.

Finally, the extent to which race influences patient care may be a function of instruments or assessment tools that lack cultural equivalence or sensitivity to accurately capture depression. Thus, the underdiagnosis and subsequent lack of optimal treatment of depression evinced among racially diverse adult and adolescent male and female patients may be a result of instruments that have not been validated with racially diverse adolescent samples (Nguyen et al., 2007). Thus, patients' and physicians' race may influence primary-care physicians, assessment, 
diagnosis, and treatment of depression in rural adolescent patients.

\section{Gender}

Nguyen and colleagues (2007) found a gender effect related to the diagnosis of depression and dysthymia: females were more likely to be diagnosed with depression than their male counterparts. These different rates of diagnosis seem inconsistent with actual prevalence rates of depression. In one study composed of rural adolescent patients, male adolescent patients had higher rates of baseline depression than female patients (Burns et al., 2004). In another study, the researchers found no difference in prevalence rates for depression between adolescent boys and girls; however, they did report differences in the presenting symptomatology, with girls reporting greater sleep and body image disturbances, higher rates of problems with concentration, and higher rates of guilt and self-blame than their male counterparts (Bennett et al., 2005). Kovacs and Sherrill (2001) describe the differences in symptomatology between adolescent males and females as follows: female adolescents tend to report and exhibit more depressive-like symptoms (sadness and hypersomnia), while male adolescents tend to report and exhibit more anger, morning fatigue, and irritability related to depression.

It is unclear to what extent depression care decisions are influenced by adolescent patient gender. Several researchers suggest that depression in males is relatively undertreated, and thus many providers may have a bias against treating males. However, differences in treatment may be better explained by the differences in presentation, as previously described. Therefore, similar to issues with diagnosis and treatment of depression among racial minority adolescents, gender differences in presentation, and symptomatology rather than physician bias - may help explain less than optimal treatment from primary-care physicians (Hohmann, 1989; Needham and Crosnoe, 2005; Ryan, 2005). Other gender differences relevant to depression care are related to suicidality. Among adolescents, females are more likely to attempt suicide, but males are more likely to complete suicide (Naqvi, 2004). Thus, assessment of suicidality as a part of optimal depression care and management is critical.

\section{Age}

As previously mentioned, as age increases so too does depression symptomatology. However, if depression goes undiagnosed and treated in younger populations (eg, early adolescence), the serious and negative impact can be particularly deleterious. For example, early childhood depression serves as a risk factor for a depressive disorder in later life. A complicating factor relative to the treatment of depression in younger populations is the lack of clear empirical evidence on efficacious treatments (Luby, 2009). This may account for some primary-care physicians' cautious stance on depression care among younger populations. Toward this end, a recent seminal study (Zuckerbrot et al., 2007a) found that older adolescents are more likely to receive treatment than younger adolescents $(45.0 \%$ versus $35.5 \%$, respectively). It is critical to take into account the unique developmental issues that may impact the assessment, diagnosis, and treatment of depression (Carr, 2008).

\section{Implications for adolescent depression care in rural settings}

Primary-care physicians can benefit from this review by acknowledging the most salient findings. The criticality of providing evidence-based depression care (ie, assessment, diagnosis, and treatment) cannot be overstated. The research suggests that primary-care physicians continue to fall short on providing consistent, evidence-based care for adolescent patients (U.S. Preventive Services Task Force, 2009). Moreover, primarycare physicians working in rural settings are at an increased disadvantage regarding the range of care available, with limited referral options for their adolescent patients who present with depression symptoms (Jensen, 2002). Therefore, rural primary-care physicians must be prepared with the knowledge, skills, training, and cultural competence to provide both medication treatment and office-based counseling (eg, CBT) for depressed adolescent patients. The publication, The Guidelines for the Management of Adolescent Depression in Primary Care (GLAD-PC), is one tool from which rural primary-care physicians can draw to increase their knowledge, skills, and competency in adolescent depression care. 
Moreover, primary-care physicians must do a better job of assessing and diagnosing depression in adolescent patients who present to their offices. Currently, only $38 \%$ of adolescents who present with depression receive evidence-based depression care - irrespective of the context or provider (eg, physician, psychologist, and family therapist; Substance Abuse and Mental Health Services Administration, 2004). This is likely because the adolescent-patient's depression has gone unrecognized and undiagnosed (Zuckerbrot et al., 2007a; 2007b). The recently published guidelines by the U.S. Preventive Services Task Force (2009) may be a useful resource for rural primary-care physicians on how to best screen, assess, and diagnose adolescent depression.

Primary-care physicians can translate the findings from this review into their daily practice by consistently and competently applying several recommendations. The following recommendations are put forth based on the current review of the literature:

- Primary-care physicians must use a standardized instrument for the assessment of depression. Several instruments have been reported to have clinical utility in the context of the primary-care setting, including the Beck Depression Inventory, Patient Health Questionnaire-Adolescents, and Center for Epidemiological Study Depression Scale.

- Primary-care physicians must recognize and assess for suicidal ideation and behaviors. Since depression is a major risk factor for suicidal ideation and behavior, physicians must regularly assess for suicide when treating adolescents who are diagnosed with depression. Moreover, medication treatment as compared to psychotherapy alone may put adolescents at increased risk for suicidal ideation and behavior (Vitiello et al., 2009). Interpersonal stressors (eg, family conflict, breakup with a boyfriend, or girlfriend) may also increase the risk for suicidal ideation and behavior (Vitiello et al., 2009). Other risk factors include comorbid psychiatric disorders (eg, anxiety disorders, conduct disorders, substance use disorders), medical conditions, and a family history of depression (Kessler et al., 2001; Kessler et al., 2003; Wagner, 2003).

- Primary-care physicians must continue assessing for suicidality throughout the duration of treatment for adolescent depression. As adolescent patients begin to experience some abatement of depression symptomatology from effective treatments, an aftereffect can be increased suicidal behavior (Vitiello et al., 2009). Thus, as the patient begins to feel better, risk of suicidal thoughts may increase (NIMH, n.d.). Primary-care physicians must be aware of this increased risk during treatment and assess for suicidality accordingly.

- Primary-care physicians must understand how demographic factors may influence the presentation of depression symptoms in adolescents. Age and gender appear to be particularly salient (Avenevoli and Merikangas, 2006). Older adolescent females appear more likely to experience a depressive episode than their older adolescent male counterparts (Avenevoli and Merikangas, 2006). And as age increases, so too does the severity of the depressive episodes, with adolescents aged 16 and 17 reporting the greatest severity in depression symptomatology. Primary-care physicians must also be prepared to culturally tailor their depression care as needed.

- Primary-care physicians must be prepared and competent to prescribe the appropriate medications for depression concurrent with the provision of counseling (eg, CBT or IPT). Currently, fluoxetine is the only antidepressant that has the Federal Drug Administration's approval for the treatment of adolescent depression (NIMH, n.d.).

- Primary-care physicians must consider combination therapy (ie, medication and counseling) as the first-line treatment for depression in adolescents. Owing to the differential response to depression treatments in adolescents, primary-care physicians must be aware of and competent to provide both medication and counseling.

Finally, although this review was delimited to studies conducted in the United States, researchers may glean important information from studies conducted internationally. For example, seminal reviews and studies conducted by Goodyer et al. (2008), Dubicka and Goodyer (2005), Wilkinson et al. (2009), and Hawton et al. (2002) may have transportability in the United States. Moreover, researchers and primary-care physicians may look 
to the National Institute for Clinical Excellence in the United Kingdom for additional published guidelines (see NICE, 2005) on the conduct of ethical, culturally responsive evidence-based care for adolescent depression.

\section{Conclusion}

Major depression is a debilitating disorder that is expected to become the second greatest burden of disease worldwide by 2020 (Kessler et al., 2003). Although depression is prevalent in adolescents, it is underdiagnosed and undertreated in this population, particularly in rural areas. Primary-care physicians are an important first line of defense against adolescent depression. This review shines light on patient demographic factors that may inform the development, testing, and implementation of culturally tailored interventions for primarycare rural settings. Future studies and reviews may consider recommendations and best practices for culturally and regionally tailored treatments that are acceptable, effective, and deliverable in rural primary-care settings. Telemedicine and internetbased depression care may be two viable treatment modalities for future research. Moreover, they may have utility for depression care in rural regions of the United States. Such treatments should be tested for efficacy to improve the quality of primary care for depression for adolescent patients.

\section{Acknowledgments}

Disclosure of financial support: The author received no financial support in the compiling and writing of this review article.

Statement of proprietary interest: The author has no commercial or proprietary interest in any drug, device, or equipment mentioned in the submitted article. In addition, the author has no financial or other conflicts of interest related to any said role as consultant, stockowner, etc.

\section{References}

Agency for Healthcare Research and Quality. 2009: Task force recommends screening adolescents for clinical depression. Retrieved 19 May 2009 from http://www.ahrq.gov/news/ press/pr2009/tfaddeppr.htm

Primary Health Care Research \& Development 2010; 11: 339-348
American Academy of Child and Adolescent Psychiatry. 1998: Practice parameters for the assessment and treatment of children and adolescents with depressive disorders. Journal of American Academy of Child and Adolescent Psychiatry 37, 63-83.

American Psychiatric Association. 1994: Diagnostic and statistical manual of mental disorders, fourth edition. Washington, DC: Author.

Asarnow, J.R., Jaycox, L.H., Duan, N., LaBorde, A.P., Rea, M.M., Murray, P., Anderson, M., Landon, C., Tang, L. and Wells, K.B. 2005: Effectiveness of a quality improvement intervention for adolescent depression in primary care clinics: a randomized controlled trial. Journal of the American Medical Association 293, 311-19.

Avenevoli, S. and Merikangas, K.R. 2006: Implications of highrisk family studies for prevention of depression. American Journal of Preventive Medicine 31, 126-35.

Bennett, D.S., Ambrosini, P.J., Kudes, D., Metz, C. and Rabinovich, H. 2005: Gender difference in adolescent depression: do symptoms differ for boys and girls? Journal of Affective Disorders 89, 35-44.

Brent, D.A., Holder, D., Kolko, D., Birmaher, B., Baugher, M., Roth, C., Iyengar, S. and Johnson, B.A. 1997: A clinical psychotherapy trial for adolescent depression comparing cognitive, family, and supportive therapy. Archives of General Psychiatry 54, 877-85.

Bridge, J.A., Salary, C.H., Birmaher, B., Asare, A.G. and Brent, D.A.A. 2005: The risks and benefits of antidepressant treatment for your depression. Annals of Medicine 37, 404-12.

Burns, J.J., Cottrell, L., Perkins, K., Pack, R., Stanton, B., Hobbs, G., Hobby, L., Eddy, D. and Hauschka, A. 2004: Depressive symptoms and health risk among rural adolescents. Pediatrics 113, 1313-20.

Carr, A. 2008: Depression in young people: description, assessment, and evidence-based treatment. Developmental Neurorehabilitation 11, 3-15.

Centers for Disease Control and Prevention. 2000: Youth risk behavior surveillance - United States, 1999. Morbidity and Mortality Weekly Reports 49, No. SS-5, 1-104.

Cheng, T.L., Savageau, J.A., Sattler, A.L. and DeWitt, T.G. 1993: Confidentiality in health care: a survey of knowledge, perceptions, and attitudes among high school students. Journal of the American Medical Association 269, 1404-07.

Cheung, A.H., Emslie, G.J. and Mayes, T.L. 2005: Review of the efficacy and safety of antidepressants in youth depression. Journal of Psychology and Psychiatry 46, 735-54.

Cheung, A.H., Zuckerbrot, R.A., Jensen, P.S., Ghalin, K., and Laraque, D., Stein R.E.K. and GLAD-PC Steering Group. 2007: Guidelines for adolescent depression in primary care (GLAD-PC): II. Treatment and ongoing management. Pediatrics 120, e1313-26.

Cheung, A.H., Zuckerbrot, R.A., Jensen, P.S., Stein, R.E.K., Laraque, D. and GLAD-PC Steering Group. 2008: Expert survey for the management of adolescent depression in primary care. Pediatrics 121, e101-107. 
Clarke, G., Debar, L., Lynch, F., Powell, J., Gale, J., O'Connor, E., Ludman, E., Bush, T., Lin, E.H.B., Von Korff, M. and Hertert, S. 2005: A randomized effectiveness trial of brief cognitive-behavioral therapy for depressed adolescents receiving antidepressant medication. Journal of American Academy of Child and Adolescent Psychiatry 44, 888-98.

Cuffe, S.P., Waller, J.L., Cuccaro, M.L., Pumariega, A.J. and Garrison, C.Z. 1995: Race and gender difference in the treatment of psychiatric disorders in young adolescents. Journal of the American Academy of Child and Adolescent Psychiatry 34, 1536-43.

Davis, J. 2000: Social stress and mental health in the southern Black Belt. Sociological Spectrum 20, 465-94.

Dubicka, B. and Goodyer, I. 2005: Should we prescribe antidepressants to children? Psychiatric Bulletin 29, 164-67.

Elster, A.B. and Kuznets, N.J. 1994: Guidelines for adolescent preventive services (GAPS): recommendations and rationale. Chicago: American Medical Association.

Epstein, S.A., Hooper, L.M., Weinfurt, K.P., Depuy, V., Cooper, L.A., Harless, W. and Tracy, C. 2008: Primary care physicians' evaluation and treatment of depression: results of an experimental study. Medical Care Research and Review 65, 674-95.

Frank, R.G., Hiskamp, H.A. and Pincus, H.A. 2003: Aligning incentives in the treatment of depression in primary care with evidence-based practice. Psychiatric Services 54, 682-87.

Gadomski, A., Bennett, S., Young, M. and Wissow, L.S. 2003: Guidelines for adolescent preventive services: the gaps in practice. Archives of Pediatrics and Adolescent Medicine 5, 426-32.

Goodyer, I.M., Dubicka, B., Wilkinson, P., Kelvin, R., Roberts, C., Byford, S., Breen, S., Ford, C., Barrett, B., Leech, A., Rothwell, J., White, L. and Harrington, R. 2008: A randomized controlled trial of cognitive behavior therapy in adolescents with major depression treated by selective serotonin reuptake inhibitors. The ADAPT trial. Health Technology Assessment 12, 1-80.

Greenberg, N., Boydell, K.M. and Volpe, T. 2006: Pediatric telepsychiatry in Ontario: caregiver and service provider perspectives. Journal of Behavioral Health Services and Research 33, 105-11.

Harrington, R. 2002: Managing suicidal behavior in adolescents. Psychiatry 5, 275-78.

Hawton, K., Rodham, K., Evans, E. and Weatherall, R. 2002: Deliberate self harm in adolescents: self report survey in schools in England. British Medical Journal 325, 1207-11.

Himelhoch, S. and Ehrenreich, M. 2007: Psychotherapy by primary-care providers: results of a national sample. Psychosomatics 48, 325-30.

Hohmann, A.A. 1989: Gender bias in psychotropic drug prescribing in primary care. Medical Care 27, 478-90.

Jensen, P.S. 2002: Health provider decision-making and interventions to change provider behaviors. Emotional Behavior Disorder in Youth 2, 53-79.
Kessler, R.C., Avenevoli, S. and Ries Merikangas, K. 2001: Mood disorders in children and adolescents: an epidemiologic perspective. Biological Psychiatry 15, 1002-14.

Kessler, R.C., Berglund, P., Demler, O., Jin, R., Koretz, D., Merikangas, K.R., Rush, J., Walters, E.E. and Wang, P.S. 2003: The epidemiology of major depressive disorder: results from the National Comorbidity Survey Replication (NCS-R). Journal of the American Medical Association 289, 3095-105.

Kovacs, M. and Sherrill, J.T. 2001: The psychotherapeutic management of major depressive and dysthymic disorders in childhood and adolescence: issues and prospects. In Goodyear, I.M., editor, The depressed child and adolescent, second edition. Cambridge, UK: Cambridge University Press, 325-52.

Luby, J.L. 2009: Early childhood depression. American Journal of Psychiatry 166, 974-79.

Martin, A. and Leslie, D. 2003: Trends in psychotropic medication costs for children and adolescents, 1997-2000. Archives of Pediatric Medicine 157, 997-1004.

Merwin, E., Hinton, I., Dembling, B. and Stern, S. 2003: Shortages of rural mental health professionals. Archives of Psychiatric Nursing 27, 42-51.

Mufson, L., Weissman, N.M., Morean, D. and Garfinkel, R. 1999: Efficacy of interpersonal psychotherapy for depressed adolescents. Archives of General Psychiatry 56, 573-79.

Naqvi, S. 2004: Review of child and adolescent psychiatry. Focus 2, 529-40.

National Institute for Health and Clinical Excellence (NICE). 2005: Depression in children and young people. London: National Institute for Health and Clinical Excellence http://guidance.nice.org.uk/CG28/niceguidance/pdf/English

National Institute of Mental Health. (n.d.): Searching for risk factors of suicidal events during antidepressant treatment. Retrieved 1 May 2010 from http://www.nimh.gov

Needham, B. and Crosnoe, R. 2005: Overweight status and depressive symptoms during adolescence. Journal of Adolescent Health 36, 48-55.

Neighbors, H.W., Caldwell, C., Williams, D.R., Nesse, R., Taylor, R.J., Bullard, K.M., Torres, M.S. and Jackson, J.S. 2007: Race, ethnicity, and the use of services for mental disorders. Archives of General Psychiatry 64, 485-94.

Nguyen, L., Huang, L.N., Arganza, G.F. and Liao, Q. 2007: The influence of race and ethnicity on psychiatric diagnoses and clinical characteristics of children and adolescents in children's services. Cultural Diversity and Ethnic Minority Psychology 13, 18-25.

Olfson, M., Cherry, D.K. and Fernandez-Lewis, R. 2009: Racial differences in visit duration of outpatient psychiatric visits. Archives of General Psychiatry 66, 214-23.

Olson, A.L., Kelleher, K.J., Kemper, K.J., Zuckerman, B.S., Hammond, C.S. and Dietrich, A.J. 2001: Primary care pediatricians' roles and perceived responsibilities in the identification and management of depression in children and adolescents. Ambulatory Pediatrics 1, 91-98. 
Pion, G.G., Keller, P. and McCombs, H. 1997: Mental health providers in rural and isolated areas: final report of the Ad Hoc Rural Mental Health Provider Work Group. Rockville, MD: U.S. Department of Health and Human Services.

President's New Freedom Commission on Mental Health. (n.d.): Rural mental health workforce development. Retrieved 1 August 2007 from http://www.Annapoliscoalition. org/rural_workforce_issues.php

Probst, J.C., Moore, C.G., Glover, S.H. and Samuels, M.E. 2004: Person and place: the compounding effects of race/ethnicity and rurality on health. Public Health 94, 1695-703.

Richardson, L.P. and Katzenellenbogen, R. 2005: Childhood and adolescent depression: the role of primary care providers in diagnosis and treatment. Current Problems in Pediatric and Adolescent Health Care 35, 6-24.

Roberts, R.E., Roberts, C.R. and Chen, Y.R. 1997: Ethnocultural differences in prevalence of adolescent depression. American Journal of Community Psychology 25, 95-110.

Rushton, J.L., Clark, S.J. and Free, G.L. 2000: Primary care role in the management of childhood depression: a comparison of pediatricians and family physicians. Pediatrics 105, 957-62.

Ryan, N.D. 2005: Treatment of depression in children and adolescents. The Lancet 366, 933-40.

Satcher, D. 1999: Mental health: a report of the surgeon general. Rockville, MD: US Department of Health and Human Services. Retrieved 1 August 2007 from http://www. surgeongeneral.gov/library/mentalhealth/home.html

Schulman, K.A., Berlin, J.A., Harless, W., Kerner, J.F., Sistrunk, S., Gersh, B.J., Dube, R., Taleghani, C.K., Burke, J.E., Williams, S., Eisenberg, J.M., Escarce, J.J. and Ayers, W. 1999: The effect of race and sex on physicians' recommendations for cardiac catherization. New England Journal of Medicine 340, 618-26.

Shirley, A. 1995: Special needs of vulnerable and underserved populations: models, existing and proposed, to meet them. Pediatrics 96, 859-63.

Stein, R.E.K., Zitner, L.E. and Jensen, P.S. 2006: Interventions for adolescent depression in primary care. Pediatrics 118, $669-83$.

Substance Abuse and Mental Health Services Administration. 2004: National survey on drug use and health. Washington, DC: Author.
U.S. Department of Health and Human Services. 2001: Healthy people 2010. McLean, VA: International Medical Publishing.

U.S. Preventive Services Task Force. 2009: Screening for child and adolescent depression in primary care settings: a systematic evidence review for the U.S. preventive services task force. Pediatrics 123, 1223-228. doi:10.1542/peds.2008-2381.

Vitiello, B., Silva, S., Rhode, P., Kratochvil, C., Kennard, B., Reinecke, M., Mayes, T., Posner, K., May, D.E. and March, J.S. 2009: Suicidal events in the treatment for adolescents with depression study (TADS). Journal of Clinical Psychiatry 70, 741-47.

Wagner, K.D. 2003: Major depression in children and adolescents. Psychiatric Annals 33, 266-70.

Walker, Z., Townsend, J., Oakley, L., Donovan, C., Smith, H., Hurst, Z. and Marshall, S. 2002: Health promotion for adolescents in primary care: randomised controlled trial. British Medical Journal 325, 524-29.

Wilkinson, P., Dubicka, B., Kelvin, R., Roberts, C. and Goodyer, I. 2009: Treated depression in adolescents: predictors of outcome at 28 weeks. British Journal of Psychiatry 194, 334-41.

Williams, D.R., Gonzalez, H.M., Neighbors, H., Nesse, R., Abelson, J.M., Sweetman, J. and Jackson, J.S. 2007: Prevalence and distribution of major depressive disorder in African Americans, Caribbean Blacks, and NonHispanic Whites. Archives of General Psychiatry 64, 305-15.

Williams, S.B., O'Connor, E.A., Eder, M. and Whitlock, E.P. 2009: Screening for child and adolescent depression in primary care settings: a systematic evidence review for the U.S. preventive services task force. Pediatrics 123, e716-735.

Zuckerbrot, R.A. and Jensen, P.S. 2006: Improving recognition of adolescent depression in primary care. Archives of Pediatrics and Adolescent Medicine 60, 694-705.

Zuckerbrot, R.A., Cheung, A.H., Jensen, P.S., Stein, R.E.K., Laraque, D. and GLAD-PC Steering Group. 2007a: Guidelines for adolescent depression in primary care (GLAD-PC): I. identification, assessment, and initial management. Pediatrics 120, e1299-1312.

Zuckerbrot, R.A., Maxon, L., Pagar, D., Davies, M., Fisher, P.W. and Shaffer, D. 2007b: Adolescent depression screening in primary care: feasibility and acceptability. Pediatrics 119, 101-108. 